\title{
Optimization of Acid Activation Conditions for Athi River Bentonite Clay and Application of the Treated Clay in Palm Oil Bleaching
}

\author{
Euphrosine Ujeneza, Helen N. Njenga , Damaris N. Mbui, David N. Kariuki \\ Department of Chemistry, University of Nairobi P.O. Box 30197-00100, Nairobi, Kenya
}

\begin{abstract}
Athi River bentonite clay was activated using sulphuric acid at various acid concentrations, clayacid ratio, temperature and contact times. Optimization was based on palm oil bleaching performance. The chemical compositions of the raw clay and clay activated at different acid concentrations were analysed to investigate the extent of cation dissolution and exchange. From the results, the clay was classified as calcium bentonite. Both cation exchange capacity (CEC) and the apparent bulk density were found to decrease with increase in acid concentration. When palm oil was bleached at $90^{\circ} \mathrm{C}$ for 30 minutes using $1 \%$ and $4 \%$ clay activated with $2 \mathrm{M}$ sulphuric acid the bleaching performances obtained were 94.5 and $98 \%$ respectively. These results compared well with those of a commercial bleaching clay which was used as standard. The equilibrium data was analysed using Freundlich and Langmuir adsorption isotherms and the former was found to provide a better fit for the data. The calculated heat of adsorption indicated that palm oil bleaching by the activated clay was an exothermic reaction and a physico-chemical process. Sulphuric acid activation was found to be an effective method of improving adsorption performance of Athi River bentonite clay and the activated product is a viable alternative to imported commercial bleaching earth.
\end{abstract}

Keywords: Acid activation, Bentonite clay, Oil bleaching, Adsorption isotherm

\section{Introduction}

The term bentonite was first used to designate a particular highly colloidal, plastic clay found near Fort Benton in the Cretaceous beds of Wyoming, USA [1]. Later the term was attributed to every plastic clay generated by the alteration of organic ash or glass emitted from volcanoes $[2,3]$.

Bleaching is an adsorption process in oil refining and the most critical stage since it helps to improve the appearance, flavour, taste and stability of the final oil products by removing coloured and colourless pigments from the oil $[4,5,6]$.

Activated bleaching earth (ABE) is the most common adsorbent for oil purification. Activated carbon and silica-based products have also been investigated for removal of pigment and impurities from oil [7]. Oil industries in Kenya use imported bleaching earth in spite of the fact that the raw material for this product is the abundantly available bentonite clay. This clay is found in many parts of the country including Athi River, Amboseli, Timau, Nanyuki, Meru and Namanga among others [8,9] Most bentonites found in nature need to undergo appropriate physical or chemical treatments such as acid activation, ion exchange and heating in order to increase surface properties, adsorption capacity, and meet a range of other application requirements $[8,10$, 11, 12]. Ajemba and Onukwuli [13] observed that activated clay adsorb colour pigments more than inactivated clay and concluded that modified clay minerals have a high potential of serving as an alternative to the most widely used and high-cost activated carbon. Farihahusnah et al, [6] reported that the high bleaching performance of bleaching earth depends on activation conditions such as acid concentration, contact time and the temperature of the activation process, all of which contribute to structural modification.

Many studies have reported successful bleaching of oil using acid activated clays from across the world $[5,14,15]$ but few have been carried out using local Kenyan clay [16]. The purpose of this study was to characterize Athi River bentonite clay and to investigate optimum conditions for acid activation and subsequently compare the activated clay with commercial bleaching earth. Bleaching performance was based on palm oil because it is the most widely used vegetable oil in Kenya. Besides developing a cost effective method for improving adsorbent properties of local clay, commercial exploitation of the clay was expected to increase income, reduce imports and contribute towards food self-sufficiency.

\section{Experimental Section}

The clay was obtained from Athi-River Mining Co. Ltd. Kenya. Crude palm oil was bought from Kapa Oil Refineries Ltd. All reagents used were analytical grade and were used without further purification. 
Experiments were performed in duplicate. The clay was washed with plenty of distilled water to remove contaminants. After drying in the oven at $105^{\circ} \mathrm{C}$, it was ground to pass through 200 mesh sieve. To determine the appropriate acid concentration, $5 \mathrm{~g}$ of clay was activated at $100^{\circ} \mathrm{C}$ for 3 hours under reflux with constant stirring using $50 \mathrm{ml}$ of $1 \mathrm{M} \mathrm{H}_{2} \mathrm{SO}_{4}$. The mixture was filtered under vacuum and washed repeatedly with distilled water until the filtrate was free of sulphate ions [12]. The sample was dried at $105^{\circ} \mathrm{C}$ and ground to a particle size that passed through 200 mesh sieve. This procedure was repeated with $2 \mathrm{M}, 3 \mathrm{M}, 4 \mathrm{M}$ and $5 \mathrm{M}$ acid concentrations. The activated clay samples were labelled A1, A2, A3, A4 and A5 where the numbers in these labels referred to the molarities of the acid used. To study the effect of activation time and temperature, the above procedure was repeated with $5 \mathrm{~g}$ clay in $50 \mathrm{ml} 2 \mathrm{M}$ sulphuric acid, varying time between 30 and 80 minutes and temperature between 100 and $120^{\circ} \mathrm{C}$ respectively. Clay-acid ratio was investigated with $5 \mathrm{M}$ sulphuric acid at $90^{\circ} \mathrm{C}$. All samples of activated clay were stored in polyethylene bags for characterization and bleaching studies.

To evaluate the performance of the activated clays, the palm oil was degummed using $0.1 \%$ phosphoric acid at $80^{\circ} \mathrm{C}$, stirred for 5 minutes, washed with distilled water and then centrifuged to remove the phosphatides. To $10 \mathrm{ml}$ of the degummed oil at $70^{\circ} \mathrm{C}, 0.1 \mathrm{~g}$ activated clay was added and the temperature was raised to $90^{\circ} \mathrm{C}$ under a stream of nitrogen. The oil was cooled to $70^{\circ} \mathrm{C}$ and then vacuum-filtered. Bleached oil absorbances were read at $450 \mathrm{~nm}$ using UV-Vis spectrometer (UV-100). Clay activation under conditions that gave best performance with $1 \%$ activated clay, was repeated with $0.05,2,3$, and $4 \%$ clay. Similar experiments were carried out with same dosages of a commercial bleaching earth used locally. Bleaching temperature was also varied between 70 and $100^{\circ} \mathrm{C}$. Raw and activated clays were analysed for chemical composition and cation exchange capacity (Varlan Spectra AA-10 spectrophotometer) [17], moisture [18], $\mathrm{pH}(\mathrm{pH} 211$, Hannah Instruments), apparent bulk density [19]. Bleached oil was analysed for free fatty acids [20, 21, 22], density (pycnometer method), oil retention [18], copper and lead (AA Spectroscopy).

\subsection{Effect of acid concentration on clay composition and structure \\ III. Results and Discussion}

Acid treatment was observed to modify the structure of bentonite as indicated by the change in the chemical composition (Table 1). Except for $\mathrm{SiO}_{2}$ whose composition rose from $46.71 \%$ to $78.52 \%$ as acid concentration was increased, the composition of other components decreased after activation. The increase in $\mathrm{SiO}_{2}$ content and a concentration decrease the for other oxides was in agreement with the results reported by Usman et al [18] and Arfaoui et al [23]. According to Diaz and Santos [15], the octahedral sheet destruction passes the exchangeable cations into the solution while the silica generated by the tetrahedral sheet remains in the solid phase due to its insolubility. The ratio of $\mathrm{Na}_{2} \mathrm{O}$ to $\mathrm{CaO}$ was 0.92 , a value less than 1 , which is indicative of the absence of swelling bentonite $[3,18]$. Therefore, the clay was classified as calcium bentonite.

Table 1: Chemical composition and loss on ignition (LOI) of raw and acid activated Athi River bentonite clay, and commercial bleaching earth (CBE)

\begin{tabular}{|c|c|c|c|c|c|c|c|}
\hline & & \multicolumn{2}{|c|}{ Athi River bentonite clay activated with $\mathrm{H}_{2} \mathrm{SO}_{4}$} & \multirow{2}{*}{ CBE } \\
\cline { 3 - 7 } \% Oxide content & Raw clay & $1 \mathrm{M}$ & $2 \mathrm{M}$ & $3 \mathrm{M}$ & $4 \mathrm{M}$ & $5 \mathrm{M}$ & \\
\hline $\mathrm{SiO}_{2}$ & 46.71 & 60.03 & 69.45 & 74.8 & 78.52 & 78.34 & 62.89 \\
\hline $\mathrm{Al}_{2} \mathrm{O}_{3}$ & 15.96 & 13.75 & 9 & 6.8 & 5.31 & 4.13 & 12.68 \\
\hline $\mathrm{CaO}$ & 4.09 & 0.57 & 0.58 & 0.6 & 0.83 & 0.63 & 0.457 \\
\hline $\mathrm{MgO}$ & 1.53 & 0.4 & 0.33 & 2.7 & 0.5 & 3.6 & 1.212 \\
\hline $\mathrm{Na}_{2} \mathrm{O}$ & 3.8 & 0.98 & 1 & 1.09 & 1.12 & 1.17 & 0.397 \\
\hline $\mathrm{K}_{2} \mathrm{O}$ & 1.35 & 1.16 & 1.23 & 1.3 & 1.2 & 1.17 & 0.778 \\
\hline $\mathrm{TiO}_{2}$ & 0.65 & 0.49 & 0.12 & $\mathrm{LD}$ & $\mathrm{LD}$ & 0.82 & 0.492 \\
\hline $\mathrm{MnO}^{n}$ & 0.6 & 0.4 & 0.2 & 0.2 & 0.3 & 0.2 & LD \\
\hline $\mathrm{Fe}_{2} \mathrm{O}_{3}$ & 7.86 & 4.09 & 1.37 & 0.71 & 0.36 & 0.22 & 3.742 \\
\hline $\mathrm{LOI}$ & 14.56 & 17.58 & 16.58 & 11.26 & 10.42 & 9.39 & 17.25 \\
\hline
\end{tabular}

Note: LD means the oxide content was below the detection limit.

It was observed that at first, the moisture content increased with increasing acid concentration. The acid attack increased the capacity of the clay to hold water. Subsequently, the moisture content decreased as the acid concentration was further increased to $3 \mathrm{M}$ and above. This could be attributed to the increase in porosity after partial loss of the exchangeable metal ions by hydrogen ions which have smaller volumes than the metal ions. The cation exchange capacity (CEC) was decreased by acid treatment, but at 5M, the CEC was observed to 
increase. A similar trend was observed by Ajemba and Onukwuli [13]. The apparent bulk density decreased to a minimum of 0.45 at $5 \mathrm{M}$ acid concentration. These results are shown in Table 2 and Fig. 1.

Table 2: Moisture, CEC and apparent bulk density of inactivated clay and clay activated at various acid concentrations

\begin{tabular}{|l|l|l|l|l|l|l|}
\hline $\begin{array}{l}\text { Molar concentration of } \\
\text { sulphuric acid }\end{array}$ & $\begin{array}{l}\text { Inactivated } \\
\text { clay }\end{array}$ & $1 \mathrm{M}$ & $2 \mathrm{M}$ & $3 \mathrm{M}$ & $4 \mathrm{M}$ & $5 \mathrm{M}$ \\
\hline Moisture content $(\mathrm{wt} \%)$ & 5.69 & 7.58 & 7.18 & 3.45 & 3.21 & 2.38 \\
\hline CEC $\left(10^{2}(\mathrm{cmol} / \mathrm{Kg})\right.$ & 1.19 & 0.8735 & 0.5926 & 0.5846 & 0.3925 & 0.4717 \\
\hline Apparent bulk density $(\mathrm{g} / \mathrm{ml})$ & 1.025 & 0.75 & 0.6 & 0.5 & 0.46 & 0.45 \\
\hline
\end{tabular}

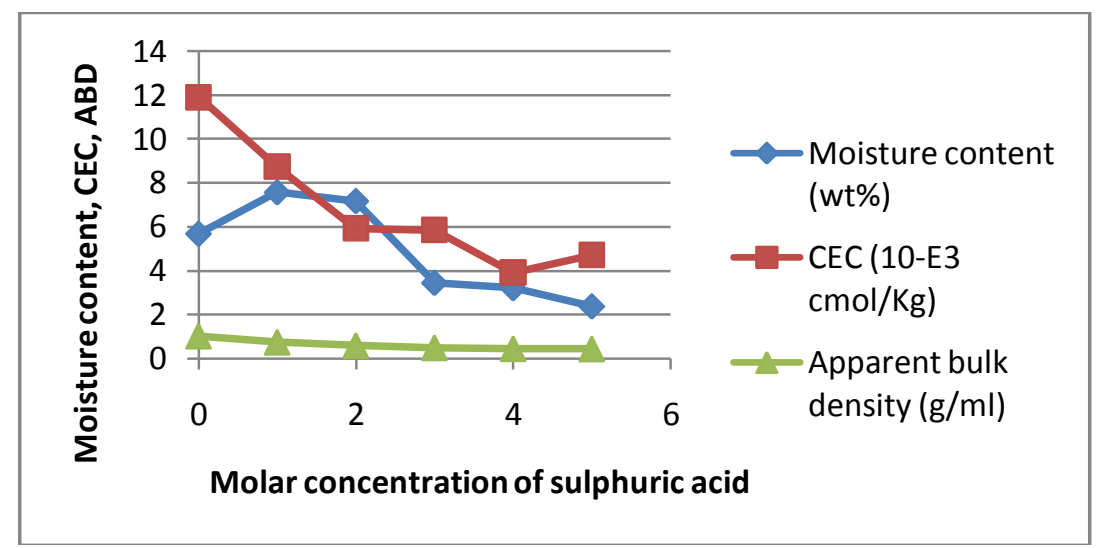

Figure 1. Effect of acid concentration on moisture content, cation exchange capacity and apparent bulk density of clay (bleaching conditions: $1 \%$ activated clay, $90^{\circ} \mathrm{C}, 30$ minutes)

\subsection{Effect of activation acid concentration on bleaching performance}

The results are presented in Fig. 2. (A1 stands for Athi River clay activated using 1M sulphuric acid). The bleaching performance first increased with the concentration of acid used up to $2 \mathrm{M} \mathrm{H}_{2} \mathrm{SO}_{4}$ and also with bleaching time up to 40 minutes. The maximum value of bleaching performance $(94.54 \%)$ was attained at $2 \mathrm{M}$ acid concentration after 30 minutes. The initial increase in bleaching performance with increasing sulphuric acid concentration was probably due to formation of active sites on bentonite surface. Subsequent decline in bleaching performance could be due to passivation of the rest of the clay, thus protecting the clay layers from further acid attack [24].

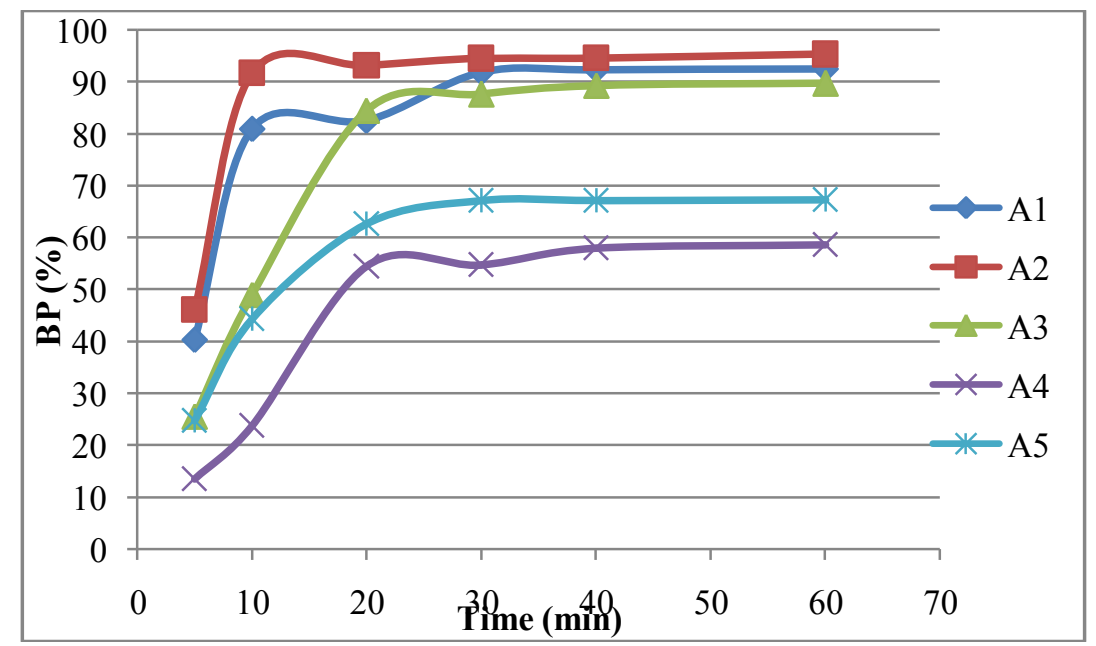

Figure 2. Effect of acid concentration and bleaching time on palm oil bleaching performance with $1 \%$ activated Athi River bentonite clay.

\subsection{Effect of clay-acid ratio}

The effect of clay-acid ratio was studied at $100^{\circ} \mathrm{C}$, with $5 \mathrm{M} \mathrm{H}_{2} \mathrm{SO}_{4}$, for 3hours. The results are shown in Fig. 3. 


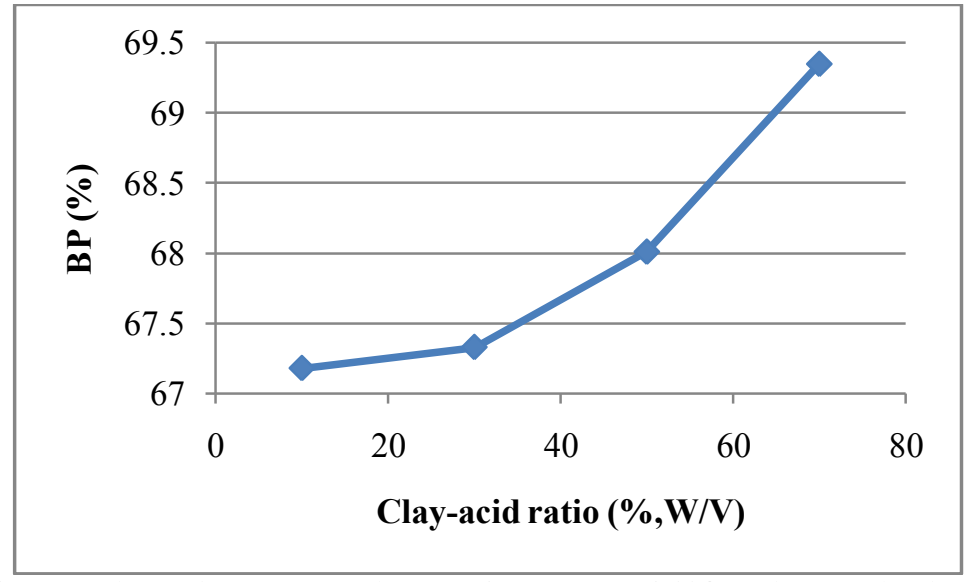

Figure 3. Effect of clay-acid ratio on bleaching performance of $1 \%$ activated Athi River bentonite clay

For this excess acid concentration found earlier on to perform poorly, bleaching performance was observed to slightly improve with increase in clay-acid ratio. When the ratio was increased from 10 to $70 \% \mathrm{w} / \mathrm{v}$, bleaching performance increased from 67.18 to 69.35 , an increase of about $2 \%$ implying a small effect on beneficiation of bentonite clay obtained at the expense of increased viscosity due to elevated high clay-acid ratio.

\subsection{Effect of activation on temperature}

The effect of temperature on activation of Athi River bentonite was investigated with $2 \mathrm{M} \mathrm{H}_{2} \mathrm{SO}_{4}, 1: 10$ clay-acid ratio $(\mathrm{w} / \mathrm{v})$. The results of bleaching oil at $90^{\circ} \mathrm{C}$ for 30 minutes using $1 \%$ clay from samples activated at $100^{\circ} \mathrm{C}$ and $120^{\circ} \mathrm{C}$ are shown in Fig. 4 .

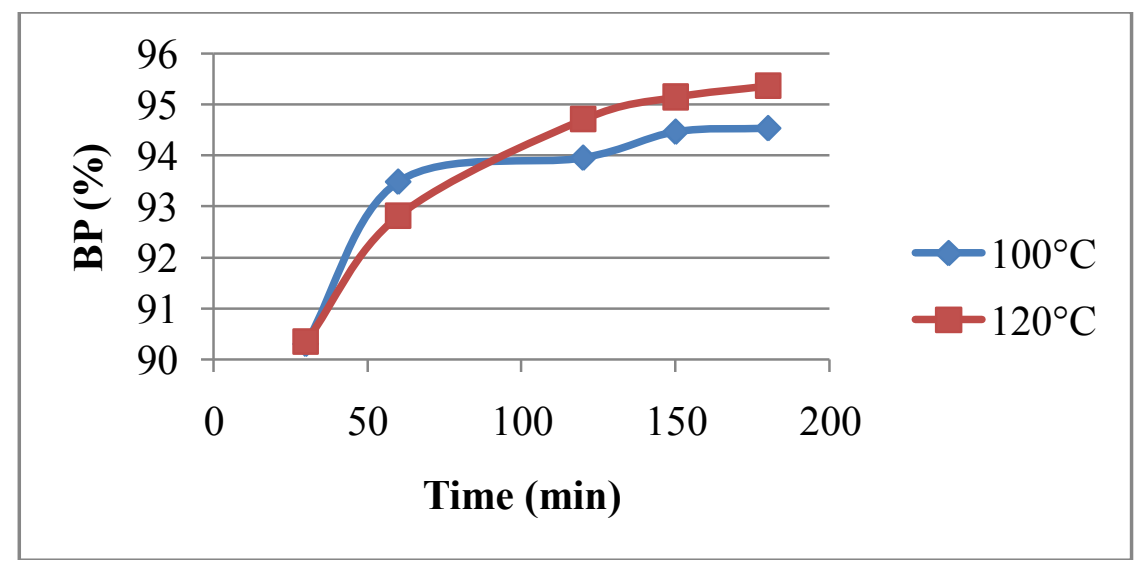

Figure 4. Effect of activation time and temperature on bleaching performance $\left(1 \%\right.$ clay at $90^{\circ} \mathrm{C}$ for 30 minutes)

The above figure shows that clay acid activation was improved by increasing temperature. This was probably due to increased speed of the molecules in the system which enhanced contact between clay surface and the acid.

\subsection{Effect of acid activation on clay colour}

As shown in Fig. 5, the colour of the clay changed from yellowish-brown to dirty white after activation at optimized conditions. 


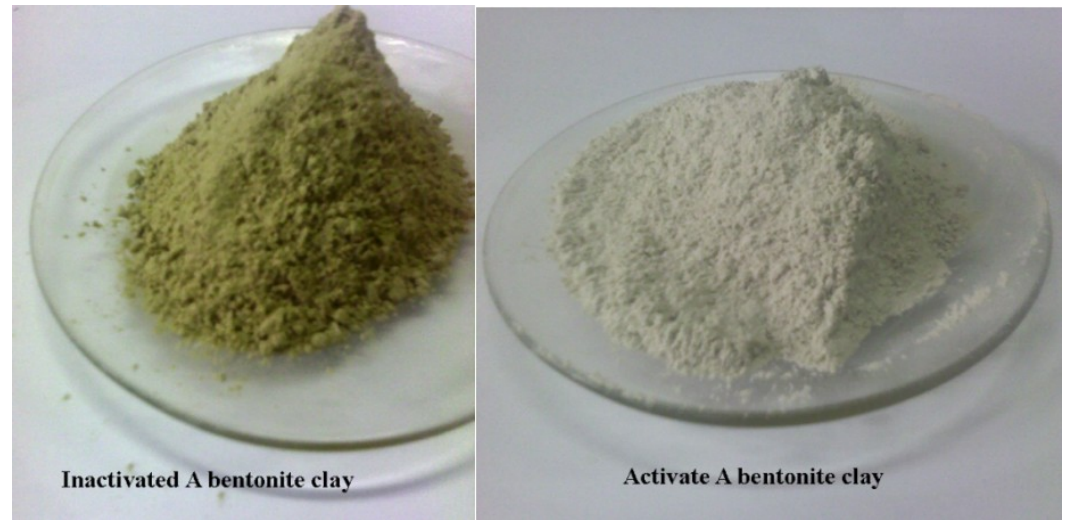

Figure 5. Raw and activated Athi River (A) bentonite clay

\subsection{Optimum bleaching conditions}

\subsubsection{Bleaching temperature}

As shown in Fig. 6, the \% bleaching performance (BP) increased with temperature to a maximum at $90^{\circ} \mathrm{C}$ followed by a drop except for sample A1 which did not show any maxima. The highest bleaching performance was obtained at $90^{\circ} \mathrm{C}$ for clay activated using $2 \mathrm{M}$ acid (Sample A2). There was a significant drop in performance for $\mathrm{A} 3$ and $\mathrm{A} 4(3 \mathrm{M}$ and $4 \mathrm{M}$ acid). After the drop, the performance remained constant. For $\mathrm{A} 3$, performance rose to $82 \%$ at $90^{\circ} \mathrm{C}$ before dropping to $65 \%$ at $120^{\circ}$. Sample A2 reached a maximum bleaching performance at $90^{\circ} \mathrm{C}$, thus performing better than commercial bleaching earth. The results are in agreement with those of Berbesi [25], who observed that bleaching temperature typically ranges between 90 and $125^{\circ} \mathrm{C}$. He also noted that oil viscosity decreases with increasing temperature resulting in better dispersion of bentonite clay particles, improved clay-oil interactions and less resistance to flow. The improved percentage pigment removal with increase in temperature was probably because of increased kinetic energy of the molecules leading to more adsorption. Adsorption reactions are generally exothermic [26] hence subsequent drop in bleaching performance with increase in temperature.

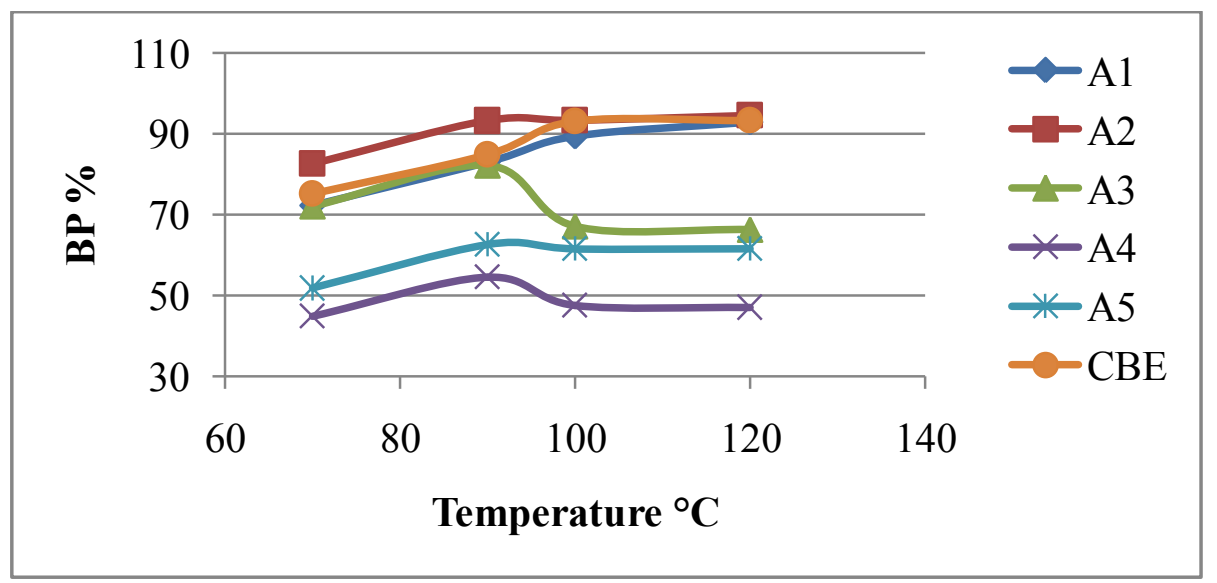

Figure 6. Effect of bleaching temperature on performance (palm oil, $1 \%$ clay at $90^{\circ} \mathrm{C}$ for 30 minutes, Athi River bentonite and commercial bleaching clay (CBE)).

\subsubsection{Effect of contact time on bleaching performance}

The results are shown in Fig. 7. Colour removal from palm oil increased with contact time. The rapid pigment adsorption in the first 5 to 20 minutes can be attributed to the increased availability of vacant surface sites at the initial stages. The optimal contact time was a maximum at 30 minutes for the various acid concentrations and this is in agreement with the results of other workers [5, 25, 27]. After 30 minutes, the adsorption was slow, implying equilibrium conditions had been attained. 


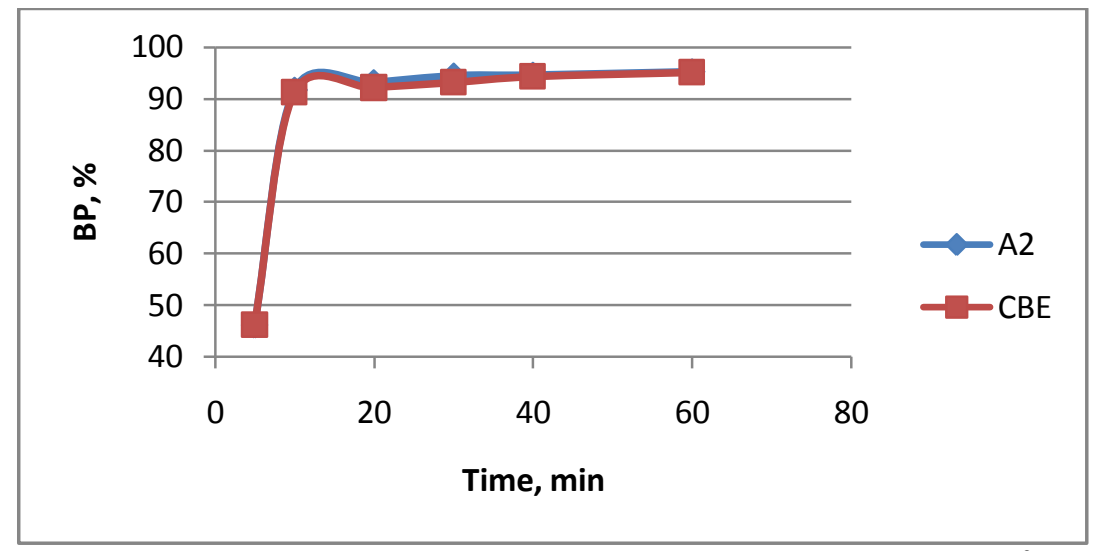

Fig. 7. Effect of bleaching time on bleaching performance (palm oil, $1 \%$ clay at $90^{\circ} \mathrm{C}$, Activated Athi River bentonite (A2) and commercial bleaching clay (CBE))

The effect of contact time on bleaching of palm oil with commercial bleaching earth (CBE) was studied for comparison with the activated local bentonite clay. It is seen from Fig. 7 that although the bleaching curve for CBE is similar to that of activated Athi River bentonite sample A2 the latter performed slightly better. Therefore, this local activated clay can be used to bleach crude vegetable oil in place of imported bleaching earth.

\subsubsection{Effect of dosage on bleaching performance}

Fig. 8 shows that the bleaching performance increased to a maximum with increasing activated clay dosage and this can be attributed to the increase in available adsorption active sites. The dosage was varied between 0.5 and $4 \%$. The bleaching performance of A2 increased from $40.32 \%$ to $98.49 \%$ and that of CBE from $46.8 \%$ to $97 \%$. It increased to an optimum value with $1-2 \%$ adsorbent dosage after which further increase in dosage had only a little effect on performance. Diaz and Santos [15] observed that darker oils like palm oil require as much as $2-4 \%$ activated clay or more to meet the colour specifications. Nwabanne and Ekwu [28] reported the increase of BP with increase in clay dosage for decolourization of palm oil using some Nigerian local clay.

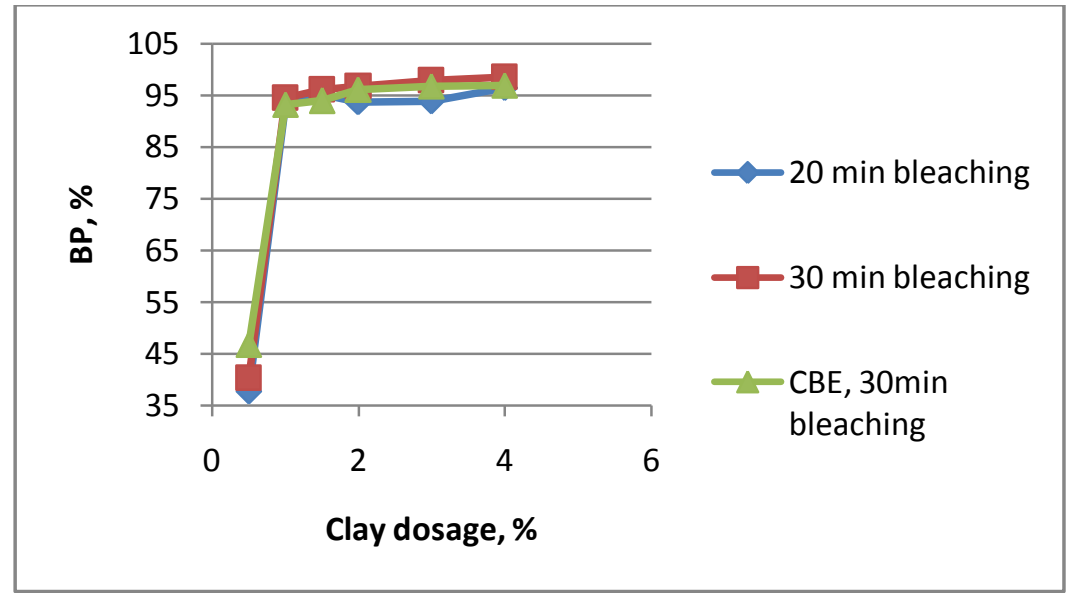

Figure 8. Effect of dosage on bleaching performance at $90^{\circ} \mathrm{C}$

\subsubsection{Adsorption isotherms}

The adsorption process data were fitted to Freundlich and Langmuir isotherms (equations 1 and 2 respectively).

$$
\log \frac{x}{m}=\log K+n \log c
$$

where $x$ is the amount of substance adsorbed, $m$ is the quantity of adsorbent and $c$ is the quantity of residual substance dissolved. $K$ and $n$ are constants unrelated to the amount of solute and adsorbent.

$$
\frac{x_{e}}{x / m}=\frac{1}{a}+\frac{b}{a} x_{e}
$$

where $\mathrm{a}$ and $\mathrm{b}$ are Langmuir constants, and are evaluated by plotting $\mathrm{x}_{\mathrm{e}} /(\mathrm{x} / \mathrm{m})$ against $\mathrm{x}_{\mathrm{e}}$. 
As has been discussed earlier, as temperature was increased, the amount of pigments adsorbed on clay surface increased. According to Ajemba et al. [28], this change occurs as a result of increased kinetic energy of the colour pigment particles, which in turn increases the frequency of collisions between the adsorbent and pigment particles and hence enhancement of adsorption on the surface of the adsorbent. Fig. 9 and 10 show the Freundlich and Langmuir isotherms for the bleaching of palm oil using the activated bentonite clay and commercial bleaching earth respectively. Freundlich isotherm gave a better fit than the Langmuir isotherm as can also be seen in Table 3 .

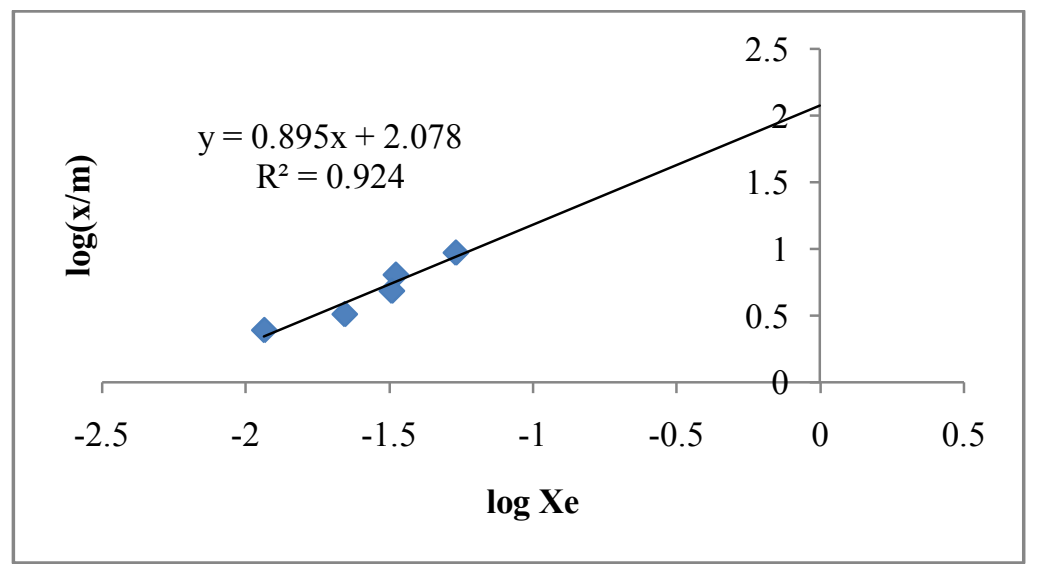

Figure 9. Freundlich adsorption isotherm for palm oil bleaching using clay activated with $2 \mathrm{M}$ sulphuric acid (Sample A2)

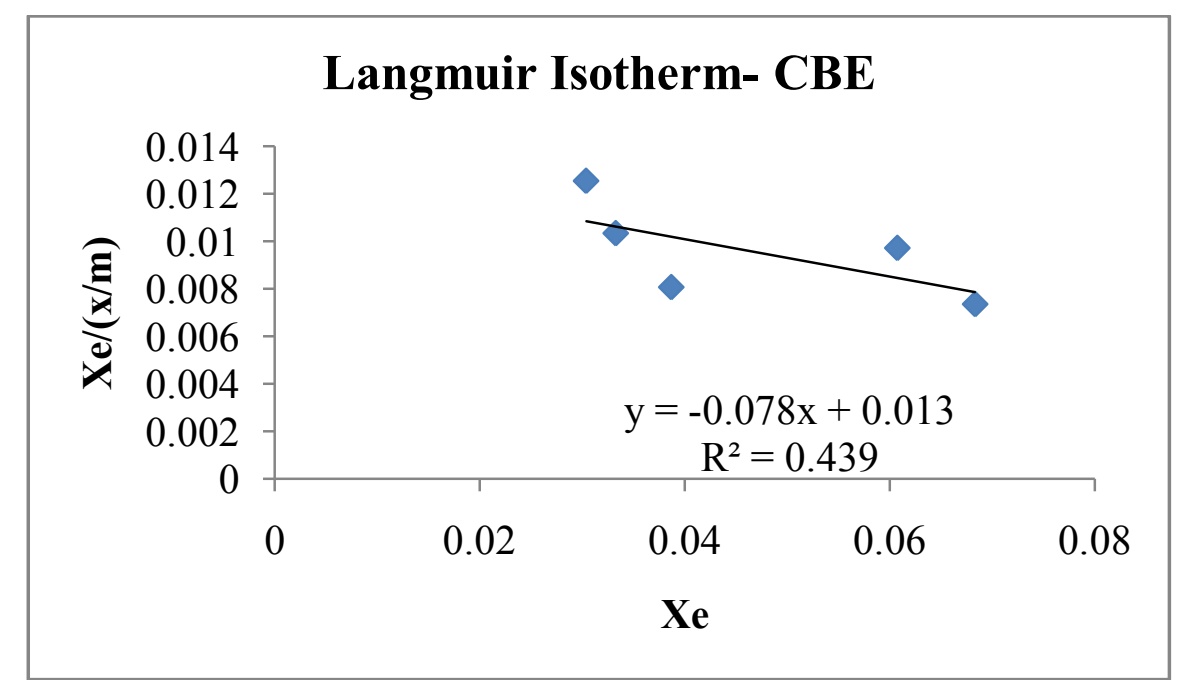

Figure 10. Langmuir adsorption isotherm for palm oil bleaching using commercial bleaching earth

Table 3:Freundlich and Langmuir isotherm constants for the bleaching of palm oil with activate Athi River clay and $\mathrm{CBE}$

\begin{tabular}{|c|c|c|c|}
\hline & Parameter & $\begin{array}{c}\text { Athi River (A) bentonite } \\
\text { clay }\end{array}$ & Commercial bleaching earth (CBE) \\
\hline Freundlich & $\mathrm{k}$ & 119.89 & 370.68 \\
& $\mathrm{n}$ & 0.8959 & 1.399 \\
& $\mathrm{R}^{2}$ & 0.9247 & 0.9175 \\
\hline Langmuir & $\mathrm{a}$. & 185.18 & 75.75 \\
& $\mathrm{~b}$ & 2.35 & -5.97 \\
& $\mathrm{R}^{2}$ & 0.0481 & 0.4393 \\
\hline
\end{tabular}

3.5.6 Heat evolved during the bleaching process

The heat evolved during the adsorption process was calculated using the following equation [29].

$$
\ln X_{e}=\frac{-\Delta H_{a}}{R T}+C
$$

where $\mathrm{X}_{\mathrm{e}}$ is the residual amount of pigment at equilibrium, $\Delta \mathrm{H}_{\mathrm{a}}$ is the heat of adsorption $(\mathrm{kJ} / \mathrm{mol})$, $\mathrm{R}$ is the gas constant $(8.314 \mathrm{~J} / \mathrm{mol} \mathrm{K}), \mathrm{T}$ is the temperature $(\mathrm{K})$, and $\mathrm{C}$ is the integration constant obtained from the plot of $\mathrm{ln}$ $X_{e}$ against 1/T as shown in Fig. 11 . 


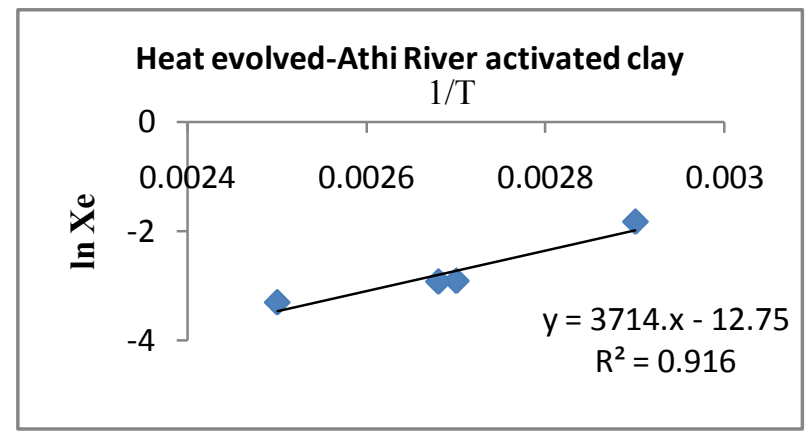

(a)

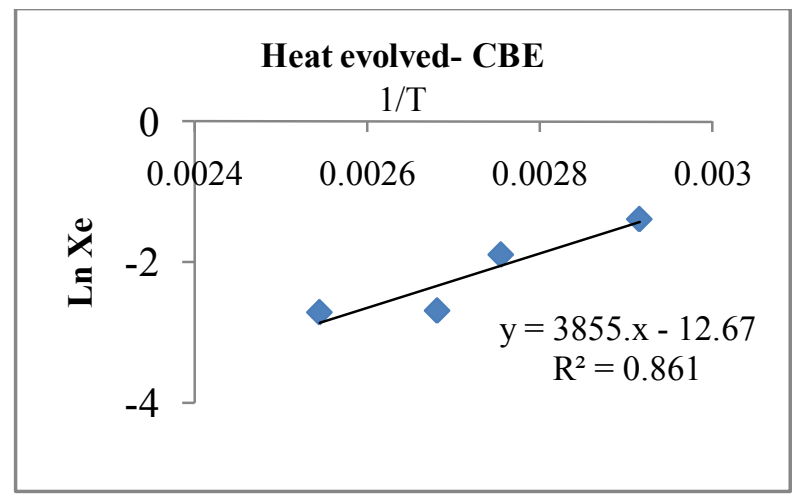

(b)

Figure 11. Plot of $\ln X_{e}$ against 1/T for sample A2 (a) and CBE (b)

The heat evolved was evaluated from Equation 7 and Fig. 11 and found to be $-30.881 \mathrm{~kJ} / \mathrm{mol}$ for A2 and $-32.05 \mathrm{~kJ} / \mathrm{mol}$ for $\mathrm{CBE}$. The negative value implies that the adsorption of pigments from palm oil onto bentonite clays is an exothermic process. $\Delta \mathrm{H}_{\mathrm{a}}$ value also indicates the type of sorption. The heat evolved during physical adsorption falls in the range of 2.1 to $20.9 \mathrm{~kJ} / \mathrm{mol}$ while that evolved during chemical adsorption is in the range of 80 to $200 \mathrm{~kJ} / \mathrm{mol}$ [29]. Therefore, since the values obtained lie between the upper value for physical adsorption and the lower value for chemical adsorption, the bleaching of palm oil by both activated Athi River clay and CBE is a physico-chemical adsorption process.

The specifications of the optimized activated bentonite clay and that of commercial bleaching earth are shown in Table 4. The oil retention for Athi River bentonite clay activated at $100^{\circ} \mathrm{C}$ with $2 \mathrm{M} \mathrm{H}_{2} \mathrm{SO}_{4}$ and for CBE was determined, and found to be $27.73 \%$ and $27.04 \%$ respectively. This is in agreement with the observation made by Rich [19], who found that clay with higher apparent bulk density value retain less amount of oil. In addition, according to Usman et al [18], this value meets commercial standards. The free fatty acid content was significantly decreased by the activated clay from 6.68 to $0.268 \%$ while commercial bleaching clay showed no effect on this parameter. Therefore the activated clay has capacity to not only bleach the oil but also to reduce the free fatty acids. In Fig. 12, the crude and bleached palm oils are shown and it is quite obvious that the bleaching process was successful.

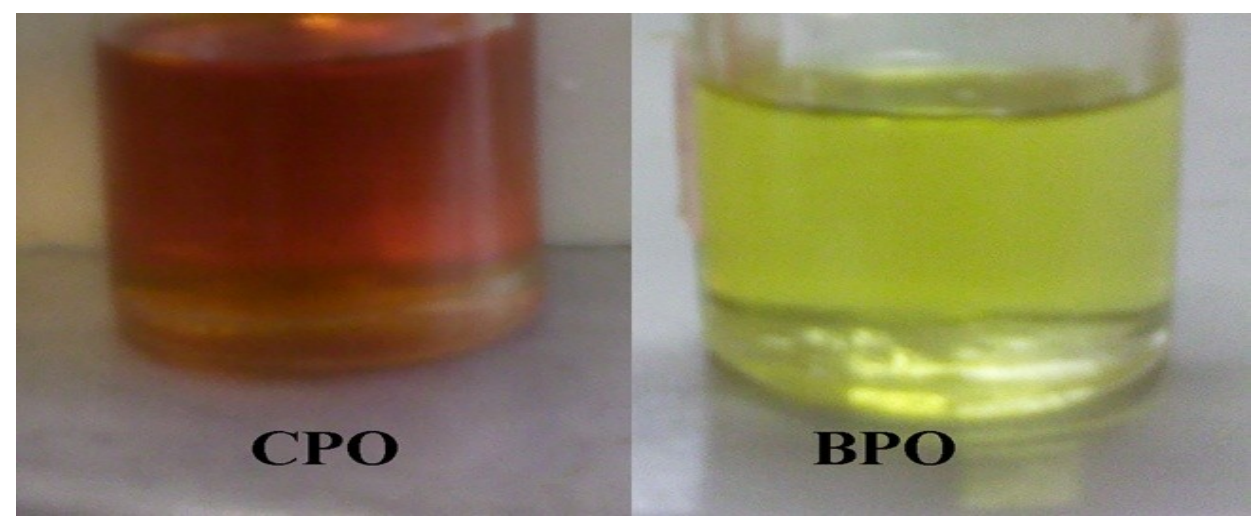

Figure 12. Unbleached (Crude palm oil) and bleached palm oil (BPO) 
Optimization of Acid Activation Conditions for Athi River Bentonite Clay and Application of the

Table 4: Quality characteristics of the raw and activated Athi River bentonite clays, and commercial bleaching earth.

\begin{tabular}{|c|c|c|c|}
\hline Clay analysis & $\begin{array}{l}\text { Raw Athi River } \\
\text { bentonite }\end{array}$ & 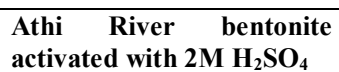 & $\begin{array}{l}\text { Commercial bleaching } \\
\text { earth }\end{array}$ \\
\hline Colour & Yellowish-brown & Dirty white & Dirty white \\
\hline Particle size & 200 mesh & 200 mesh & 200 mesh \\
\hline $\mathrm{pH}(10 \%$ in water $)$ & 10.7 & 4.35 & 3.8 \\
\hline Apparent bulk density g/l & 1024.97 & 600.68 & 715.81 \\
\hline $\begin{array}{l}\mathrm{CEC} 10^{2} \mathrm{cmol} / \mathrm{kg} \\
\text { Bleached Palm oil analysis }\end{array}$ & ND & 0.5926 & ND \\
\hline FFA content $\%$ & 6.68 & 0.268 & 6.68 \\
\hline Oil retention $\%$ & ND & 27.73 & 27.04 \\
\hline Moisture content \% & 5.69 & 7.18 & 8.3 \\
\hline $\mathrm{Cu} \mathrm{ppm}$ & ND & 470 & 465 \\
\hline $\mathrm{Pb}$ ppm & ND & 1.0 & 1.4 \\
\hline
\end{tabular}

ND: not determined

\section{Conclusion}

In this study, activated Athi River bentonite clay was assessed for its potential in bleaching of palm oil. Chemical composition allowed classification of the clay as 'calcium bentonite'. Acid activation at optimized conditions was found to significantly alter the clay structure and consequently improve the bleaching performance of the clay which compared well with that of the commercial bleaching earth. Furthermore, the activated clay was found to reduce free fatty acids from crude palm oil, unlike the commercial clay which had no effect. This study has shown that Athi River bentonite clay is a viable source of adsorbent for palm oil bleaching and a feasibility study for its exploitation is hereby recommended.

\section{References}

[1] G. B Kutlic, I. Sobota, Bentonite processing, Professional Paper 24, 2012, 61-65

[2] S. Nadežda,. L. Mihovil, L. Jelena, P. Jelena, M. Miljana, B. Biljana, M. Radosavljevi, Characterization of bentonite clay from "Greda" deposit. Processing and Application of Ceramics 5 (2), 2011, 97-101

[3] A. Basim, Rheology of sodium and calcium bentonite-water dispersions: Effect of electrolytes and aging time. Inter. Journal of Mineral Processing 98, 2011,208-213

[4] M.A. Didi, B. Makhoukhi, A. Azzouz, D. Villemin, Colza oil bleaching through optimized acid activation of bentonite: A comparative study, Applied Clay Science, 42, 2009, 336-344

[5] M.A. Usman, O. Oribayo, A.A. Adebayo, (2013) Bleaching of Palm Oil by Activated Local Bentonite and Kaolin Clay from Afashio, Edo-Nigeria, Chemical and Process Engineering Research. 10, www.iiste.org

[6] H. Farihahusnah, K.A. Mohamed., A.W.D. Wan Mohd, Textural characteristics, surface chemistry and activation of bleaching earth: A review, Chem. Eng. Jour. 170, 2011, 90-106

[7] E.M. Ejikeme, S.O. Egbuna, P.C.N. Ejikeme, Optimal bleaching performance of activated 'Ngwulangwu' clay, IJEIT, 3(5), 2013, 13-19

[8] B. Kariuki, Electrochemical behaviour of polyaniline electrodeposited on a redox ion-exchanger modified electrode. Msc Thesis University of Nairobi, 1966.

[9] P.K. Mutisya, S.M. Maranga, B.W. Ikua, An insight into the source of bentonite used in the local drilling industry, JKUAT, 20

[10] M. Rossi, M. Gianazza, C. Alamprese, F. Stanga, The role of bleaching clays and synthetic silica in palm oil physical refining, Food Chem. 82, 2003, 291-296

[11] L. Rožic, N. Tatjana, P. Srđan, Modeling and optimization process parameters of acid activation of bentonite by response surface methodology. Applied Clay Science 48, 2010, 154-158

[12] E.L. Foletto, G.C. Colazzo, C. Volzone, L.M. Porto, Sunflower oil bleaching by adsorption onto acid-activated bentonite. Brazilian Journal of Chemical Engineering 28(01), 2011, 169-174

[13] R.O. Ajemba, O.D. Onukwuli, Nitric Acid-activated Nteje Clay: Structural and Bleaching Properties Intern. Journ. of Eng. 26(5); 2013, 495-500

[14] B. Makhoukhi, M.A. Didi, D. Villemin, Modification of bentonite with diphosphonium salts: Synthesis and characterisation. Mater. Lett. 62, 2008, 2493-2496

[15] F.V. Diaz, S.P. de Souza, Studies on the acid activation of Brazilian smectitic clays. quim. Nova, 24(3), 2001, 345-353

[16] M.E. Kariuki, Determining optimal conditions for activating local bentonite clay and comparison with commercial bleaching earth. Report, University of Nairobi, 2013

[17] S.R. Donald, K. Quirine, Recommended methods for determining soil cation exchange capacity, http://extension.udel.edu/lawngarden/files/2012/10/CHAP9.pdf Retrieved on 11 September 2013

[18] M.A. Usman, V.I. Ekwueme, T.O. Alaje, A.O. Mohammed, Characterization, Acid Activation, and Bleaching Performance of Ibeshe Clay, Lagos, Nigeria, ISRN Ceramics, 2012 1-5

[19] A.D. Rich, Relationship between the apparent bulk density of a bleaching clay and its oil retention, JAOCS, 7(6), 1960, 305-307

[20] G. Worthen (1938) Isopropyl alcohol as a solvent for free fatty acid titration, Oil \& Soap, 15(7), 1983, 189-190

[21] B.M.Z. Rohani, N.A.M. Madia, M.K.A. Madya, Process design in degumming and bleaching of Palm oil. Universiti Teknologi Malaysia, 2006

[22] Lubrizol test procedure (2010), Determination of acid value and free fatty acid, Lubrizol Advanced Materials Inc.

[23] S. Arfaoui, N, Frini-Srasra, E. Srasra, Modelling of the adsorption of the chromium ion by modified clays, Desalination, 222(1-3), 2008, 474-481

[24] G. Christidis, P. Scott, A. Dunham, Acid activation and bleaching capacity of bentonites from the islands of Milos and Chios, Aegean, Greece, Applied Clay Science, (12) 4, 1997, 329-347 
[25] R. Berbesi, (2006) Achieving Optimal Bleaching Performance, Oil Mill Gazetteer, 2006, 112, 2-6

[26] J. Walter, J.R. Weber, Adsorption Processes (PAC- IUPAC Publications, 1974)

[27] J.T. Nwabanne, F.C. Ekwu, Decolourizing of palm oil by Nigerian local clay: A study of adsorption Isotherms and bleaching kinetics, Intern. Journ. of Mult.Sci and Eng. (1), 2013, 20-25

[28] R.O. Ajemba, P.K. Igbokwe, O.D. Onukwuli, (2012) Kinetics, equilibrium studies of colour pigments removal from palm oil using activated Ukpor clay, Appl. Sci. Res., 4 (5), 2012, 1958-1966

[29] H. Topallar (1998) The Adsorption Isotherms of the Bleaching of Sunflower-Seed Oil. Tr. J. of Chemistry 22, 1998, 143-148 